\title{
Politics in the Process of Establishing Local Development Plan: Case Study of the Lan Tak Fah Subdistrict Administrative Organization, Nakornchaisri, Nakornpathom, Thailand
}

\author{
Kittisak Jermsittiparsert ${ }^{1}$, Annop Atsadamongkhon ${ }^{2} \&$ Thanaporn Sriyakul ${ }^{3}$ \\ ${ }^{1}$ Faculty of Political Science, College of Government, Rangsit University, Thailand \\ ${ }^{2}$ Department of Industrial Works, Ministry of Industry, Thailand \\ ${ }^{3}$ Faculty of Business Administration, Mahanakorn University of Technology, Thailand \\ ${ }^{4}$ Political Science Association of Kasetsart University, Thailand \\ Correspondence: Kittisak Jermsittiparsert, Faculty of Political Science, College of Government, Rangsit \\ University, Thailand. Tel: 66-866-222-495. E-mail: kittisak.j@rsu.ac.th
}

\author{
Received: July 28, 2015 Accepted: August 13, $2015 \quad$ Online Published: October 14, 2015 \\ doi:10.5539/res.v7n12p75 URL: http://dx.doi.org/10.5539/res.v7n12p75
}

\begin{abstract}
This research study aims at studying the politics in the process of establishing a local development plan of the Lan Tak Fah Subdistrict Administrative Organization, Nakornchaisri, Nakornpathom, Thailand by qualitative methodology, including documentary and field research. One of the findings is although Thailand's local administration is established under the principle of decentralization, where local peoples' needs will be most directly addressed, the process of establishing the development plan of the Lan Tak Fah Subdistrict Administrative Organization, from strategy selection to implementation, is in fact based on the government's strategies and guidelines. They cover not only the central government's strategies/guidelines, that is (1) National Economic and Social Development Plan (No. 11) 2012-2016 and (2) the government's policy, but also the regional government's ones, that is (1) the provincial development strategy, (2) the community plan, and (3) policy framework, direction, and development guideline of local administrative organizations and Nakornpathom Province. The opportunities open for the Subdistrict peoples' needs to be expressed were merely (1) review of problems and needs from the past years and (2) expressions of further needs in the present year in the form of projects. Moreover, other factors, including publicities, community meetings, especially in making decisions to select projects, and budget allocation, are significant causes of the local development planning process to become a tool for the Subdistrict Administrative Organization to make peoples only the "margin of development." The entire process, therefore, made the Subdistrict's peoples become disinterested in and inattentive from such process. In the end, there is a tendency that peoples will continuously less participate in the process of local development planning. Accordingly, the important recommendation for reform should not limit only to changes in local administrations but also modifications in the central and regional governments' administrations, as appropriate.
\end{abstract}

Keywords: decentralization, Lan Tak Fah subdistrict administrative organization, local development plan, policy network, political participation

\section{Background and Significance of the Problem}

\subsection{Participation of Peoples in the Process of Local Development Planning}

As editors of the compilation of academic articles on "Challenges in Decentralization and Local Administrations in Thailand," Charas Suwannamala and Weerasak Kruatep (2011) stated in the introduction that "decentralization of powers to local administrative organizations has been more significant in the past decades. Many missions in providing public services and managing the government's resources have been transferred to the responsibilities of local administrative organizations. Academic issues and implications to the practicalities at present are: What is the progress of carrying decentralization forward? What are limitations, challenges, or obstacles? How should local administrative organizations modify their roles and duties? Do local administrative organizations possess preparedness and competency in providing public services and managing in resources, finance, politics and 
administrations? When there are problems or obstacles under various subjects, how can solutions or ways of dealing with problems or limitations be found?".

Throughout different analyses, institutional measures, and macro-level policies which have been raised and compiled in nine articles, the interesting point, which is obvious but hardly receives any interest, is that the status and role of "community meetings" for participations in budget planning in subdistrict administrative organizations "do not actually lead to the satisfactory expected outcomes." This in turn causes "peoples to have doubts in participations in community meetings with local administrative organizations because they could not see that participations in such meetings would render any objective outcome." Some even consider that "occasionally, community meetings become a tool to give legitimacy to local administrative organizations' executives, who have already made a decision on how to allocate the budget in advance." Therefore, "community meetings turn to be simply a stage to transfer information from the executives of local administrative organizations to peoples, not the actual "consultations" stage for peoples to discuss with officers." (Suwannamala \& Kruatep, 2011).

The researchers' literature review relating to local development planning during the past decade does not indicate any profound research study as well as there has been none of further expansion or development of knowledge in any case study. The past studies, for instance, "Provincial Administrative Organizations" (Unchaoban \& Chujit, 2008; Lertkrai, 2014); “City Municipalities" (Bunleng, 2005; Kaew-hanam, 2012); "Municipalities" (Munkit, 2008; Yumwilai, 2011); "Subdistrict Municipalities" (Yoongtong, 2012; Tapanadhamchai, 2013) as well as "Subdistrict Administrative Organizations" (Chairat, 2011; Chotkunpan, 2011; Boontongkum, 2012; Kulnapan, 2012; Tapthani, 2012; Sabua, 2013; Kaewpangmak and Galantapura, 2014; Sriwongsa and Charoensuk, 2014), are simply based on the paradigm of giving much significances to peoples' participations in local development planning. This is because such idea is the key principle of politics and administrations in a democratic system, which usually opens opportunities for peoples to reflect their needs to the closet government agencies so that their needs can finally be responded immediately and directly.

However, the interesting fact is that almost all of those studies only focus on surveys of the levels of participation, be it participations in finding problems/needs, in analysis of problems/needs, in planning and execution of plans, in implementation of work plans, or even in follow-ups and assessments. When superficially considered, such focus seems to lead to a clearer conclusion of peoples' participations in the public affairs. Nevertheless, when looking at those studies closely, the researchers find that those conclusions with regard to the levels of peoples' participation as "maximum level, high level, medium level, low level, and minimum level" are not actually closely related to interpretation of frequency averages of the opinions of survey respondents in 4.51-5.00, 3.51-4.50, 2.52-3.50, 1.51-2.50, and 1.00-1.50 (Srisa-art, 1992). Moreover, the efforts in explaining the averages of frequencies to closely link to corresponding levels of participations are actually only an acknowledgement of levels of peoples' participations, not real levels of peoples' participations.

\subsection{Lan Tak Fah Subdistrict Administrative Organization, Nakornchaisri, Nakornpathom, Thailand}

Lan Tak Fah was originally part of Ngew Rai, Nakronchaisri, Nakornpathom, Thailand. Because Ngew Rai had a large area and later the population increased immensely, a new subdistrict called Lan Tak Fah was separated, with the total area of 19.20 square kilometers or approximately 12,000 Rai. To the north is Bang Kaew Fah and Huay Plu of Nakornchaisri; to the south is Ngew Rai of Nakornchaisri; to the east is Klong Yong and Mahasawat of Bhuddamonton; and to the west is Don Fak and Samrong of Nakornchaisri. The topography of the Subdistrict is a basin, proper for agriculture because it is a green area with rains all year long and the Nakornchaisri River passing through, and a lot of canals. Majority of the population are farmers, especially rice farmers, with the total area of rice fields of 5,000 Rai. The second occupation is fruit gardeners, such as guavas, rose apples, pomelos, jackfruits, mangoes, and vegetables, as well as gardeners of orchids and flowering and ornamental plants. The area of gardens totals approximately 1,100 Rai. Many people also make a living by fisheries, such as shrimp and fish aquaculture.

Lan Tak Fah was established the Lan Tak Fah Subdistrict Administrative Organization under the decree of the Ministry of Interior dated 19 January 1996. At present (2014), there are 2,666 family households accounting for the total population of 7,418, with 3,453 males and 3,965 females. The population density averages at 386 people/square kilometers. They live in five villages (so-called Moo): Moo 1, Baan Klong Jek, with the area of approximately 2300 Rai. Most of the land is basin with total population of 594 from 162 households. Majority of people are in agriculture, such as rice farming, vegetable gardening, and orchid gardening. Moo 2, Baan Lum Tahan, with the area of around 2,100 Rai. Total population is at 836 people from 214 households. Main occupations are rice farming, lotus farming, vegetable gardening, and orchid gardening. Moo 3, Baan Lan Tak 
Fah, with approximately 4,000 Rai of land and 1,100 population. The land is suitable for agriculture and most of the population make a living by rice farming, vegetable gardening, fruit gardening, and shrimp aquiculture. Moo 4, Baan Tai Wat, the approximate land area of 1,600 Rai, a basin next to the river and population of 777 from 301 households. The land is also suitable for rice farming, shrimp aquaculture and gardening. Lastly, Moo 5, Baan Bang Keng of the area 2,000 Rai with the total population of 4,101 from 1,681 households.

The facts above show that there have been conditions of changes in the subdistrict and in the structure and dispersion of the population. More than half of the total population reside in Moo 5, especially in Prueksa Villages 4 and 8, which account for less than one sixth of the subdistrict area. It thus indicates that people moved from rural communities, where most are in agriculture with low density of population, to the urban communities, where most people are in non-agriculture sectors with high density of population. Differences in occupations and topographies definitely results in different conditions of peoples' problems and needs. (Kruatep, 2010) Interestingly, "policy making process", one of the best tools to reflect "politics" in the local administrations (Sirorod, 2014) through allocation of limited resources in order to address the unlimited needs of peoples, is also indicating the totally different needs of people.

\subsection{Research Questions}

This research aims at studying politics in the process of establishing a local development plan of the Lan Tak Fah Subdistrict Administrative Organization. Such as, how does the process work? Who has participated in the policy process? Other particular focuses are selection of strategies and development guidelines, publicities, community meetings, selection of projects and budget allocation. In addition, the status and role of different groups, especially peoples of the subdistrict, through the whole process, presented in the form of policy networks.

\section{Research Method}

\subsection{Research Design}

This research employs qualitative research methodology. The researchers conducted their work in two following parts:

(1) Documentary research: information research from documents, including primary sources, such as laws, regulations, requirements, decrees, and meeting reports of government agencies, secondary sources, such as books, textbooks, manuals, research studies, articles, as well as relevant electronic database, in order to gather theories and relevant research findings to form concept frameworks for this study, as well as analyses of information from field research.

(2) Field research: gathering of information from the methods of participant observation, key informant in-depth interview, focus group, in order to obtain facts about politics in the process of establishing the local development plan of the Lan Tak Fah Subdistrict Administrative Organization.

\subsection{Participants of the Research}

Participants consist of: 1) one person from the executive of the Lak Tak Fah Subdistrict Administrative Organization, Chief of the Subdistrict Administrative Organization; 2) two persons from the legislative, that is Council members of the Subdistrict Administrative Organization from Moo 5; 3) two officers from the Subdistrict Administrative Organization, that is the Permanent Secretary and Chief of the Permanent Secretary Office of the Subdistrict Administrative Organization; 4) one community leader, that is President of the Community Enterprise of the Community Deed in Klongyone-Lan Tak Fah; and 5) eight Lan Tak Fah people from Moo 2, Moo 4 and Moo 5.

\subsection{Collection of Data}

Documentary research: research conducted on the issues of rules, regulations, requirements, manuals, meeting reports of relevant different agencies, such as the Act on Stipulating Plans and Procedure of Decentralization to Local Administrative Organizations 1999, Ministry of Interior's Regulation on Establishing and Coordinating Local Development Plan 2003, Ministry of Interior's Regulation on Establishing Local Development Plan of Local Administrative Organization 2005, Ministry of Interior's Regulation on Establishing and Coordinating Local Development Plan 2005, Manual for Establishing Local Development Plan, Strategic Plan for Development, Three-Year Development Plan, Implementation Plan and Monitoring and Assessment by the Department of Local Administration, reports of community meetings in the village to establish Development Strategic Plan (2015-2019) and Three-Year Development Plan (2015-2017) of the Lan Tak Fah Subdistrict Administrative Organization.

Field research: gathering of practical information from local development planning and the establishment of 
local development plan of the Lan Tak Fah Subdistrict Administrative Organization, especially people's participation and roles of other relevant people as follows:

(1) Participant observation in the second community meeting to establish the Development Strategic Plan (2015-2020) and the Three-Year Development Plan (2015-2017) on Monday 24 February 2014 at 9:30-10:10 hrs. at Buddhadhammarungsi Monastery Moo 1 and the third meeting on Monday 24 February 2014 at 13:30-13:30 hrs at the Community Learning Centre Moo 2 to observe behaviors of the attendees of the community meetings.

(2) Interview of executives, Council members and officers of the Lan Tak Fah Subdistrict Administrative Organization, as well as the community leaders and people from different villages totaling 10 people as follows:

(3) Group conversation with four people living in Moo 2 on 24 November 2014: 1) Kanueng Muangpo-ngern; 2) Taweepong Pason; 3) Nong Sawaddee; and 4) Boonlue Pason.

Table 1. Names of interviewees

\begin{tabular}{|c|c|c|c|}
\hline & Name-Surname & Title & Date of Interview \\
\hline 1 & Chalor Promsoongwong & Citizen living in Moo 2 & 21 November 2014 \\
\hline 2 & Sun Supivek & $\begin{array}{l}\text { Chief of the Subdistrict Administrative } \\
\text { Organization }\end{array}$ & 28 November 2014 \\
\hline 3 & Vorachai Wattanakornkaew & $\begin{array}{l}\text { Council Member of the Subdistrict } \\
\text { Administrative Organization, Moo } 5\end{array}$ & 28 November 2014 \\
\hline 4 & Rinawat Sangtong & $\begin{array}{l}\text { Council Member of the Subdistrict } \\
\text { Administrative Organization, Moo } 5\end{array}$ & 28 November 2014 \\
\hline 5 & Sasitorn Siripin & Citizen living in Moo 4 & 28 November 2014 \\
\hline 6 & Napapat Dongtongsang & Citizen living in Moo 5 & 28 November 2014 \\
\hline 7 & Sangpen Tongsima & Citizen living in Moo 5 & 28 November 2014 \\
\hline 8 & Nanta Prasanwong & $\begin{array}{l}\text { President of the Baan Chanode Community } \\
\text { Enterprise of Klongyone Community-Lan } \\
\text { Tak Fah }\end{array}$ & 28 November 2014 \\
\hline 9 & Viriya Sinkasem & $\begin{array}{l}\text { Permanent Secretary of the Subdistrict } \\
\text { Administrative Organization }\end{array}$ & 1 December 2014 \\
\hline 10 & Sakkarin Chuket & $\begin{array}{l}\text { Acting Chief of the Permanent Secretary } \\
\text { Office of the Subdistrict Administrative } \\
\text { Organization }\end{array}$ & 1 December 2014 \\
\hline
\end{tabular}

\section{Research Results}

\subsection{Process in Establishing the Development Plan of the Lan Tak Fah Subdistrict Administrative Organization}

\subsubsection{Process in Establishing the Development Strategic Plan 2015-2019}

The report of community meetings in establishing the Development Strategic Plan (2015-2019) and the Three-Year Development Plan (2015-2017) of the Lan Tak Fah Subdistrict Administrative Organization from Sunday 23 to Tuesday 25 February 2014 divides the procedure of establishing the development plan of the Lan Tak Fah Subdistrict Administrative Organization into two parts: (1) in making the Development Strategic Plan for 2015-2019 and (2) in establishing the Three-year Development Plan 2015-2017, with the detail in the process of setting up these plans related to rules and regulations by law and in practice as follows: 
Table 2. Detail on community meetings

\begin{tabular}{llllll}
\hline Order & Moo & Dates & Hours & Venue & Number of participants \\
\hline 1 & 5 & 23 February 2014 & $09.00-11.00$ & Brahma Square & 138 \\
2 & 1 & 24 February 2014 & $09.00-10.30$ & Wat Bhuddhammarunsi & 86 \\
3 & 2 & 24 February 2014 & $13.00-14.00$ & Community Learning Centre & 49 \\
4 & 3 & 25 February 2014 & $09.00-11.00$ & Community Shop & 91 \\
5 & 4 & 25 February 2014 & $13.00-14.30$ & Community Shop & 44 \\
\hline
\end{tabular}

The Manual for Establishing Local Development Plan, Strategic Plan for Development, Three-Year Development Plan, Implementation Plan and Monitoring and Assessment, prepared by Local Development Division, Bureau of Local Development and Management Promotion, Department of Local Administration, indicates nine following steps to be taken in establishing a development strategic plan:

(1) preparation for an establishment of the development strategic plan; (2) gathering of information and important problems; (3) analysis of potentials to assess the status of local development at present; (4) identification of visions and missions in local development; (5) identification of goals for sustainable development; (6) designation of objectives of local development; (7) designation and integration of guidelines for local development; (8) identification of the targets of local development. After the consideration process and improvement by different relevant agencies, the executives of local administrative organization will submit to the Council for an approval. Afterwards, the executives of the local administrative organization will issue it to be effective.

However, the actual steps taken at the Lan Tak Fah Subdistrict Administrative Organization started from the Committee to Support the Establishment of Development Plan for the Subdistrict Administrative Organization produced a draft development strategic plan (2015-2019) and submitted to the local executives. The Committee considered (1) the National Economic and Social Development Plan (No. 11) 2012-2559; (2) the government policy; (3) the provincial development strategy; (4) the community plan; and (5) the direction policy framework and guideline for development and local administrative organization and Nakornpathom in setting the development strategy. Total of six strategies with 48 development guidelines are covered.

In the community meeting report, it is merely indicated that a policy and plan analysis officer of the subdistrict administrative organization explained the people the detail of abovementioned development strategic planning before the entire community meetings of five villages, during 23-25 February 2014, agreed to it. The researchers observed that at least in the second community meeting in the morning of Monday 24 February 2014 at Buddhadhammarungsi, of Moo 1 and Moo 3 and in the afternoon of the same day at the Community Learning Centre Moo 2, there was neither explanation nor opportunity for people to approve this matter.

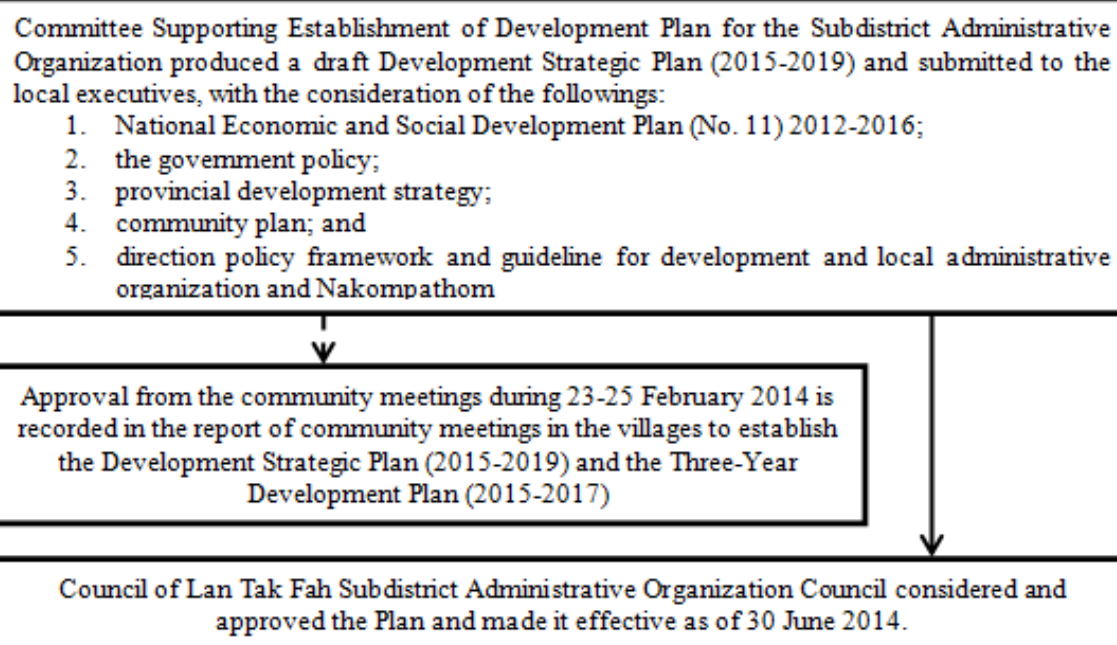

Council of Lan Tak Fah Subdistrict Administrative Organization Council considered and approved the Plan and made it effective as of 30 June 2014.

Figure 1. Process in establishing the Development Strategic Plan (2015-2019) 


\subsubsection{Process in Establishing the Three-Year Development Plan 2015-2017}

While the process in making the Strategic Plan 2015-2019 of the Lan Tak Fah Subdistrict Administrative Organization did not closely follow the procedure in producing a development strategic plan as provided for in the Manual of Department of Local Administration, the actual process in establishing the Three-Year Development Plan 2015-2017 relatively followed the written guideline, indicating five steps: (1) preparation for establishing the Three-Year Development Plan; (2) production of the draft Three-Year Development Plan; (3) consideration of the Three-Year Development Plan draft in order to submit to the local executives; (4) approval and implementation of the Plan; and (5) implementation of the Plan.

The work in establishing the Plan Three-Year Development 2015-2019 of the Lan tak Fah Subdistrict Administrative Organization was carried out in the meetings which took place on the same days of community meetings for the Five-Year Development Plan (2015-2019) during 23-25 February 2014 under the Strategic Framework and Guideline for the Draft Strategic Plan 2015-2019. People were given an opportunity to participate in two ways: (1) review of the needs from the past years which have not yet been fulfilled; and (2) submission of new projects, and then taking a decision in prioritizing those projects under two categories. The projects would be considered along with the draft Three-Year Subdistrict Administrative Organization Development Plan, which was drafted by Committee Supporting Establishment of Development Plan for the Subdistrict Administrative Organization. Later, all the documents were submitted to the Council of subdistrict administrative organization for approval before the Chief of the subdistrict administrative organization approved and announced it to be effective on 30 June 2014.

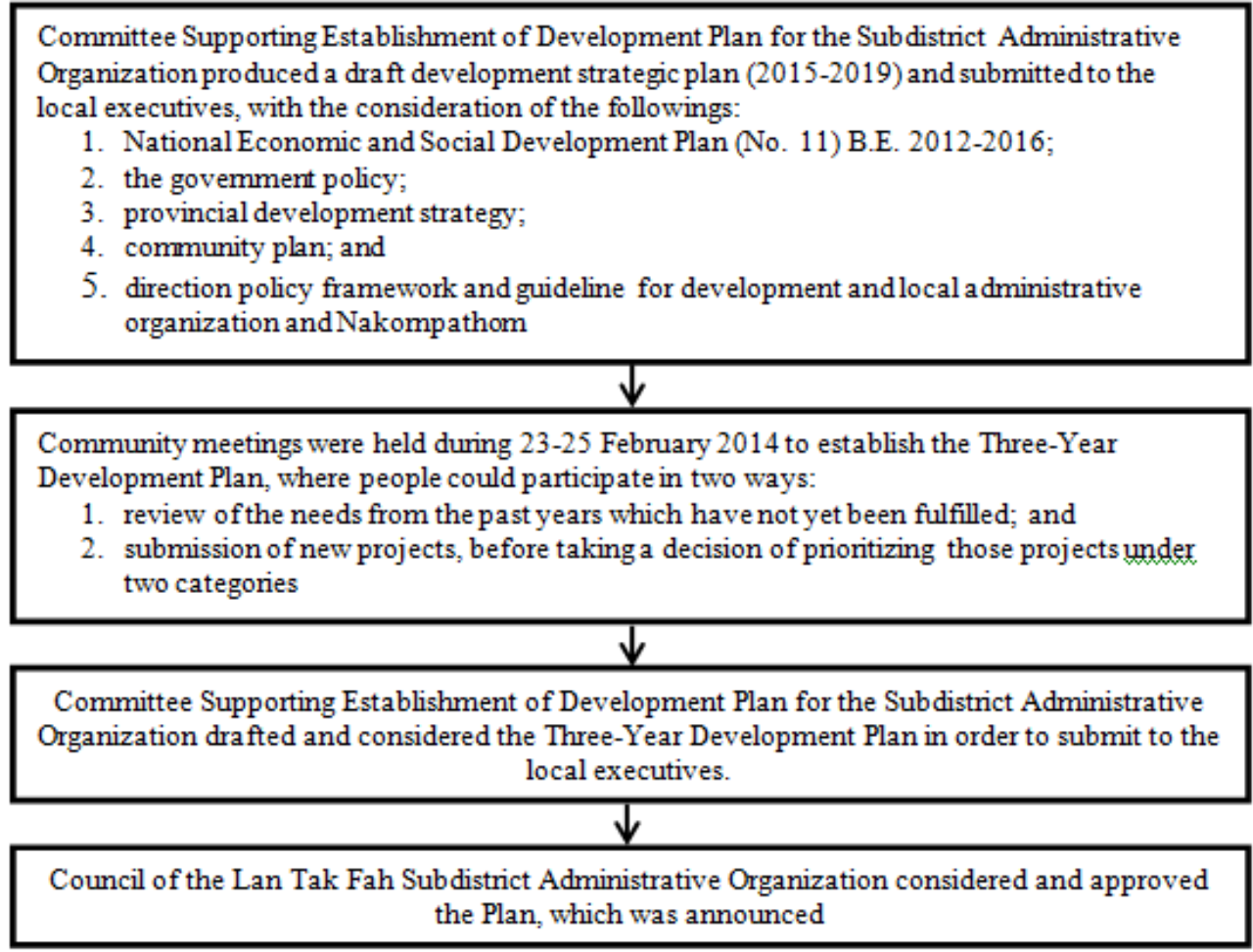

Figure 2. Process in Establishing the Three-Year Development Plan 2015-2017

\subsection{Publicities}

As the community meetings to establish the local development plan is considered "another forum in which peoples in the locality can participate in the process," (Chotkunpan, 2011), that is, to put it into words clearly, people can participate in the process of allocations of resources or budgets of their subdistrict administrative organization, from the beginning process of public relations. The executives of the Lan Tak Fah Subdistrict Administrative Organization reaffirmed that "letters were sent to every household by mail and cost 7,000 baht in total for the whole subdistrict" (Supivek, 2014), which is consistent with the officer's statement providing that "there was an explanation...publicity. Letters were sent via post. There were posters, publicity vans but not at a high percentage" (Chuket, 2014). In any case, "mostly there would be letters sent, and later subdistrict heads 
and/or village chiefs would announce to their people about the programs, dates and times of the community meetings." (Sinkasem, 2014).

However, some subdistrict people argued that they did not receive any letter or any news from any publicity van, but only "by word of mouth, which is difficult to reach everyone." (Siripin, 2014). This is also consistent with the remark of one Council member of the subdistrict administrative organization that "whatever they have, they have never done any publicity or post any sign for people to see." (Wattanakornkaew, 2014). It is possible that "[because] if you publicize, people will know and why wouldn't they be interested! It's about their everyday's living...but you intentionally did not do publicity and no news reached people, because with publicities, there need to be principles in explaining information. Vans to sell pork are better than this as they have loud speakers to announce." (Wattanakornkaew, 2014) The community leader, who was a Council member of the subdistrict administrative organization elaborated the political dimension regarding publicities by emphasizing that "establishing" the plan can be done by "taking the most relatives to the meetings as possible." (Prasanwong, 2014) Under the current situation in which not many people participate in the community meetings, with "not many new faces" and actually "fewer faces" each time (Tongsima, 2014), "establishing" and/or "taking around twenty relatives to join the meeting is quite enough" (Prasanwong, 2014). This has quite significant effect to the submission and selection of projects to be contained in the Three-Year Development Plan of the Subdistrict Administrative Organization.

\subsection{Community Meetings in the Villages}

The result of this minimal publicity level with the information not reaching everyone as well as establishing/bringing others along by Council members of the Subdistrict Administrative Organization, subdistrict/village leaders, and community leaders in each village, is most people came to the community meetings owing to "understanding...being afraid of not being polite because they were asked to go, and having others to think for us that this matter is related to us, we should include this, we should vote this. This is for our village, we should do this." (Prasanwong, 2014).

At the meeting, people would have an opportunity to express their needs in two ways: (1) reviewing the needs in the past years which have not yet been addressed for around 5-8 projects; and (2) proposing 5-10 new projects. Then, these projects would be ordered by necessities and emergencies and, in the end, decided to be included in the Three-Year Development Plan. This approach is criticized that "there were [projects] people did not vote for, which seemed like they were all set up...most of them, who has the same interests as leaders, came to help vote as well." (Tongsima, 2014).

After analyzing the names of participants in the village community meeting Moo 2, where only 34 people showed up (Note 1), I it is found that the relationships of participants in the community meeting and negotiating power of networks in the village between the group of one Council member of the Subdistrict Administrative Organization, Somsak Niamsang and the other group of the (previous) village leader, Singh Tongseetong, father of Surasangkart Tongseetong, the current village leader Moo 2. During the meeting, not only would Tongseetong be the one who expressed his opinion almost the whole time, but all the participants appeared to have some network or relationship with Tongseetong.

Table 3. Names of participants at the community meeting in Moo 2 with indications of relationships or reasons to participate in the meeting

\begin{tabular}{ll}
\hline Names & Relationship \\
\hline Boonnak Muaenwongdham & $\begin{array}{l}\text { wife of Subdistrict Administrative Organization Council Member (Somsak } \\
\text { Niamsang) }\end{array}$ \\
Chaliew Chuensangjun & $\begin{array}{l}\text { close to Subdistrict Administrative Organization Council Member (Somsak } \\
\text { Niamsang) }\end{array}$ \\
Pong Muaenwongdham & uncle of Boonnak Muaenwongdham \\
Supote Poonnayom & close to previous village leader (Singh Tongseetong) \\
Keysorn Sanorkum & close to previous village leader (Singh Tongseetong) \\
Pondpawee Piromruen & close to previous village leader (Singh Tongseetong) \\
Linjee Poonnayom & sister of Keysorn Sanorkum
\end{tabular}


Toon Promsoongwong

Sommart Piamsuwan

Singh Tongseetong

Panat Duangsanoe

La-or Iamsuwan

Wong Iamsuwan

Sind Tinsakorn

Anant Duangsanoe

Boonsri Yodsrika

Prasit Ninpoetong

Prapai Chinsa-nguan

Pratuaeng Muangpoe-nguen
Assistant Subdistrict Headman

close to previous village leader (Singh Tongseetong)

father of current village leader (Surasangkart Tongseetong)

close to previous village leader (Singh Tongseetong)

wife of older brother of Tawin Iamsuwan / election canvasser of previous village leader (Singh Tongseetong) and father-in-law of Subdistrict Administrative Organization Council Member (Sureerat Sonsaka)

aunt of Tawin Iamsuwan

aunt of Tawin Iamsuwan

close to previous village leader (Singh Tongseetong)

close to previous village leader (Singh Tongseetong)

assistant Village Headman

wife of Prasit Ninpoetong

son of sibling of wife of previous village leader (Singh Tongseetong)

\subsection{Decision Making in Selecting Projects and Budget Allocation}

Almost all of the projects proposed in the community meetings during February 2014 were placed in the Three-Year Development Plan 2015-2017 of the Lan Tak Fah Subdistrict Administrative Organization. Nevertheless, the placement in such Plan “does not mean the projects would be implemented." (Supivek, 2014) The administration of the subdistrict administrative organization explained to people that "because it depends on the money," that is if "the support money is not there, then no implementation." (Supivek, 2014) This is a repetitive pointless expectation, that is, out of many projects placed in the Plan, only 1-2 projects were proceeded and the view of subdistrict administrative organization's administration expressed that "2 projects are already very good." (Supivek, 2014) With this, village people feel that "it is not at all concrete, not tangible, so why would we do it?" (Siripin, 2014) It seems like in the past, how the subdistrict administrative organization responded to people's needs was only "putting the projects in the plan, but did not do anything else seriously," (Dongtongsang, 2014); accordingly, "it does not at all help as it is not about the writing but depends on the executive people if they would do it or not!" (Siripin, 2014)

On the other hand, the administration of the subdistrict administrative organization often claimed that "if it is not in the plan, we cannot do it" (Supivek, 2014) because "if any project is not included in this plan, the subdistrict administrative organization does not have any right to proceed" (Supivek, 2014). Consequently, people becomes disadvantageous through the whole process because the current mechanism for peoples' participation in the establishment of the subdistrict administrative organization development plan allows the administration of the subdistrict administrative organization to use the conditions of development plan from development strategic plan, which is based on the national development strategic framework, but does not allow for any negotiations space for people. Until the Three-Year Development Plan, only a small number of projects were initiated by people and those would need an effort to be placed in the implementation plan. Even fewer projects are actually implemented. Due to being pushed to be at the "border of development process" in the community, village people would start seeing no benefits in the short term, feeling in vain to participate in the process, and then in the medium term, would tend to avoid the process of making development plan of the subdistrict administrative organization. In the long term, it is likely that people will be completely pushed away from this process.

Considering the summary of the number of projects and the budget in the implementation plan of the fiscal year 2014 of the Lan Tak Fah Subdistrict Administrative Organization, the researchers found that approximately 70 percent of the fiscal year 2014 budget which links to the Three-Year Development Plan of the subdistrict administrative organization is allocated to the guidelines for development and promotion of welfare for the executives, Council members, officers, employees, and workers (33.19 percent); development of work process, improvement, and development of technology, equipments and buildings (36.23 percent). On the contrary, the development strategy in five areas was allocated for only 16.51 percent of the budget, that is, (1) education, religions, and cultures (9.30 percent); (2) economic development (0.22 percent); (3) social development (3.86 percent); (4) environment and tourism (0.38 percent); and (5) public services (2.75 percent). 


\subsection{On the Development Plan of the Lan Tak Fah Subdistrict Administrative Organization}

As discussed, the process in establishing a local development plan was closely governed and regulated by the central government significance is put on (1) National Economic and Social Development Plan (No. 11) 2012-2016 and (2) the government policy) and the regional government (consisting of (1) the provincial development strategy; (2) the community plan; and (3) the policy framework, direction, and development guideline of local administrative organization and Nakornpathom), and no opportunities were given to people to actually participate in the process. The Development Strategic Plan (2015-2020), with six strategies and 48 guidelines, are detailed as follows:

Strategy 1: Development on education, religions, and cultures, which comprises 6 development guidelines: (1) develop education and promote sustainable educational system; (2) promote functions to show respect to His Majesty the King and national ceremonies; (3) promote and support learning centers and news and information channels; (4) promote and support dissemination and practice in religions, ethics, cultures, customs, and traditional knowledge; (5) preservation of cultures, archaeological sites, antiques, local museums, and religious sites; and 6) promote and support culture monitoring in families, schools and communities.

Strategy 2: Economic development, consisting of 4 guidelines: (1) develop, promote and train people relating to their occupations; (2) promote and support production/agriculture produce without toxic substance, community products, and SME industries; (3) promote and support economic development following the sufficient economy guidance of His Majesty the King; and (4) promote and support development of alternative energy and saving energy.

Strategy 3: Social development, comprising 8 guidelines: (1) promote and support sports and recreations; (2) promote and support public health work; (3) resolve, prevent, and fight against drugs; (4) promote and support social development and social welfare work; (5) protect and keep peace and order in the country and security in life and property; (6) promote and support disaster relief work, procure materials, hardware, and equipment in disaster relief work, and (7) enhance strength in families and communities; and (8) enhance unity in the society.

Strategy 4: Development in environment and tourism, consisting of 6 guidelines: (1) develop, promote, and support conversation of natural resources and environment and reduce pollution; (2) protect rivers, canals, and different water resources, and prevent floods and polluted water; (3) maintain and develop public areas; (4) develop and promote cultural, ecological, and health tourisms; (5) develop and promote areas with potentials in tourism to become new tourist attractions; and (6) be prepared to deal with natural disasters.

Strategy 5: Development with regard to good governance, comprising 9 guidelines: (1) develop good governance in entities, promote participations of people in local development, and support the government under democratic system; (2) promote good governance, present and suppress corruptions and misconducts in the government; (3) support welfare for the executive, and assist the local administrative organizations, Council members of the subdistrict administrative organization, officials, employees, and workers; (4) improve and develop the capability and work culture of personnel; (5) support, improve, and develop information technology, equipment, and buildings; (6) promote knowledge and understanding about the local work; (7) improve and develop income and manage the government assets that has not been used for the maximum benefits; (8) increase efficiency of the internal audit; and (9) support and promote development work in order to enhance the national security, the community judicial procedure, and dispute settlement with peaceful means.

Strategy 6: Public service development, consisting of 5 guidelines: (1) build, improve, and maintain roads, bridges, bicycle lanes, drains, ports, garbage management system, and waste water treatment system, and repair and improve public facilities which are damaged from disasters; (2) develop the traffic system and transportation; (3) develop electricity and waterworks; (4) promote, support, establish a city plan, overall city plan, specific city plan, and prevent trespass of public areas; and (5) develop water resources, canals, and the irrigation system for consumptions, agriculture and other usages.

As for the projects which were considered in the community meetings in order to place them in the Three-Year Development Plan 2015-2017, they can be categorized to two parts: (1) review of projects in the past years which have not been implemented and (2) additional projects proposed this year.

Category (1) projects by village: Moo 1, eight projects: (1) improve waterworks; (2) build a stage in the community hall; (3) build speed bumps on reinforced-concrete road in front of the house of elderly Payom; (4) build a non-asphalt road passing Uncle Chuay's for 600 metres; (3) build a reinforced-concrete road connecting Don Fak Subdistrict; (6) procure a water pump with a drainage pipe; (7) support traditional and cultural activities in the village; and (8) support women groups, agriculture groups and elderly groups. Moo 2, five projects: (1) 
provide for wire broadcasting; (2) build an asphalt road along Chai Kan Canal; (3) install electric lights on the roadside of Sabar Canal and Chai Kan Canal; (4) build a reinforced-concrete bridge in the area of Mr. Amnuay's house; and (5) expand the bridge crossing Lum Ta Harn Canal. Moo 3, five projects: (1) improve waterworks and groundwater; (2) improve and add more roadside lights on every street; (3) build a reinforced-concrete road at the second part of the north area; (4) improve every road along canals; and (5) improve and repair wire broadcasting. Moo 4, five projects: (1) build a reinforced-concrete road on Kratoom-Muaeg Route and build bridges crossing canals; (2) build wire broadcasting; (3) support housewife and occupational groups; (4) support work of the community welfare fund; and (5) support different traditional and cultural activities. Moo 5, six projects: (1) install exercise equipments which are up to standard; (2) improve the public facilities system; (3) establish a news and information centre; (4) prevent and solve drug problems; (5) install fire extinguishers with training on how to use them; and (6) promote occupations of people.

Category (2) projects by village and orders according to priorities: Moo 1, four projects: (1) to install surveillance cameras; (2) to improve the waterworks system; (3) to build speed bumps on reinforced-concrete roads; (4) to fill red earth on the road for Uncle Chuay's house; and (5) to improve the bridge at Uncle Gae's house and the bridge-neck of the Bang Ra Chan Canal bridge. Moo 2, six projects: (1) to arrange water pipes from iron pipes to polyethylene pipes; (2) to build a road along Chai Kan Canal; (3) to build a reinforced-concrete bridge in the area of Mr. Amnuay's house; (4) to expand the bridge crossing Lum Ta Harn Canal; (5) to repair asphalt roads by using asphalt instead of crushed rocks; and (6) to install wire broadcasting. Moo 3, ten projects: (1) to improve all roads along the side of canals in Moo 1-5; (2) to improve the waterworks system in Moo 1-5; (3) to improve the electric lights on roadsides in Moo 1-5; (4) to build a bus-waiting hall at Grandma Pond's house; (5) to put crushed rocks on the road of Pracha Ruam Jai Route; (6) to dredge Ton Sai Canal and remove weeds; (7) to repair Kwai Canal Hall; (8) to install convex traffic mirrors to reduce road accidents; (9) to improve and repair roads with big puddles; and (10) to install electric lights in the area of the Yong Canal wood bridge. Moo 4, eight projects: (1) to build a reinforced-concrete bridge crossing Kratoom-Muaeg Canal; (2) to improve the waterworks system, and wash pipes and tanks; (3) to build a reinforced-concrete road in the area of Kratoom-Muaeg Canal; (4) to install wire broadcasting; (5) to support work of the social welfare fund; (6) to support occupational and housewife groups; (7) to support different traditional activities; and (8) to install roadside lights from Mr. Tarm's house to Mr. Surin's. Moo 5, five projects: (1) to resolve garbage problems in the village; (2) to establish a news and information centre; (3) to improve and repair electric lights in the village; (4) to install exercise equipments; and (5) to improve the waterworks system (outside the village).

When incorporating the Development Strategic Plan with the projects from the past years which have not been implemented and additional projects for this year, the Lan Tak Fah Subdistrict Administrative Organization established the Three-Year Development Plan 2015-2017 which consists of 164 projects, 31 of which are the projects proposed in the community meetings out of the total of 36 projects.

\section{Conclusion and Discussions of the Research Outcome}

Michael (1974) stated that decentralization of power is the movement of power away from the center. In theory, local administration is expected to better cater to the needs of people in the localities. However, the process in establishing the development plan of the Lan Tak Fah Subdistrict Administrative Organization, from the step of choosing the strategies to developing guidelines, is mainly based on the government's strategies and guidelines, by setting six strategies with 36 development guidelines. Moreover, the process only opens the space for people to express their needs only by reviewing the problems and needs from the past years for approximately 5-8 projects and proposing additional projects in the present year for 5-10 projects.

It should also be noted that more than $5 / 6$ of the total budget of the fiscal year 2014, which is connected to the Three-Year Development Plan of the subdistrict administrative organization, is allocated to development and promotion of the welfare of the executive people, the Subdistrict Administrative Organization Council members, officials, employees, and workers and development and promotion of the work, improving and developing technology, equipment, and buildings. On the other hand, less than $1 / 6$ of the budget is used in development strategies in five areas, that is, (1) education, religions, and cultures; (2) economic development; (3) social development; (4) environment and tourism; and (5) public services. Besides this imbalanced budget allocation, the Three-Year Development Plan is utilized as the tool of the subdistrict administrative organization to push over the people to become only the "border of development", resulting in people becoming inattentive and detaching from the system and tending to continuously less participate in the process of local development planning. 
In summary regarding the politics in the process of establishing the local development plan, this case study of the Lan Tak Fah Subdistrict Administrative Organization reveals the interactions between different segments of the overall picture, from the central government, to the regional and local governments, as well as community leaders, peoples in the locality, different political groups in the province, and other subdistrict administrative organizations, as appeared in Figure 3 below:

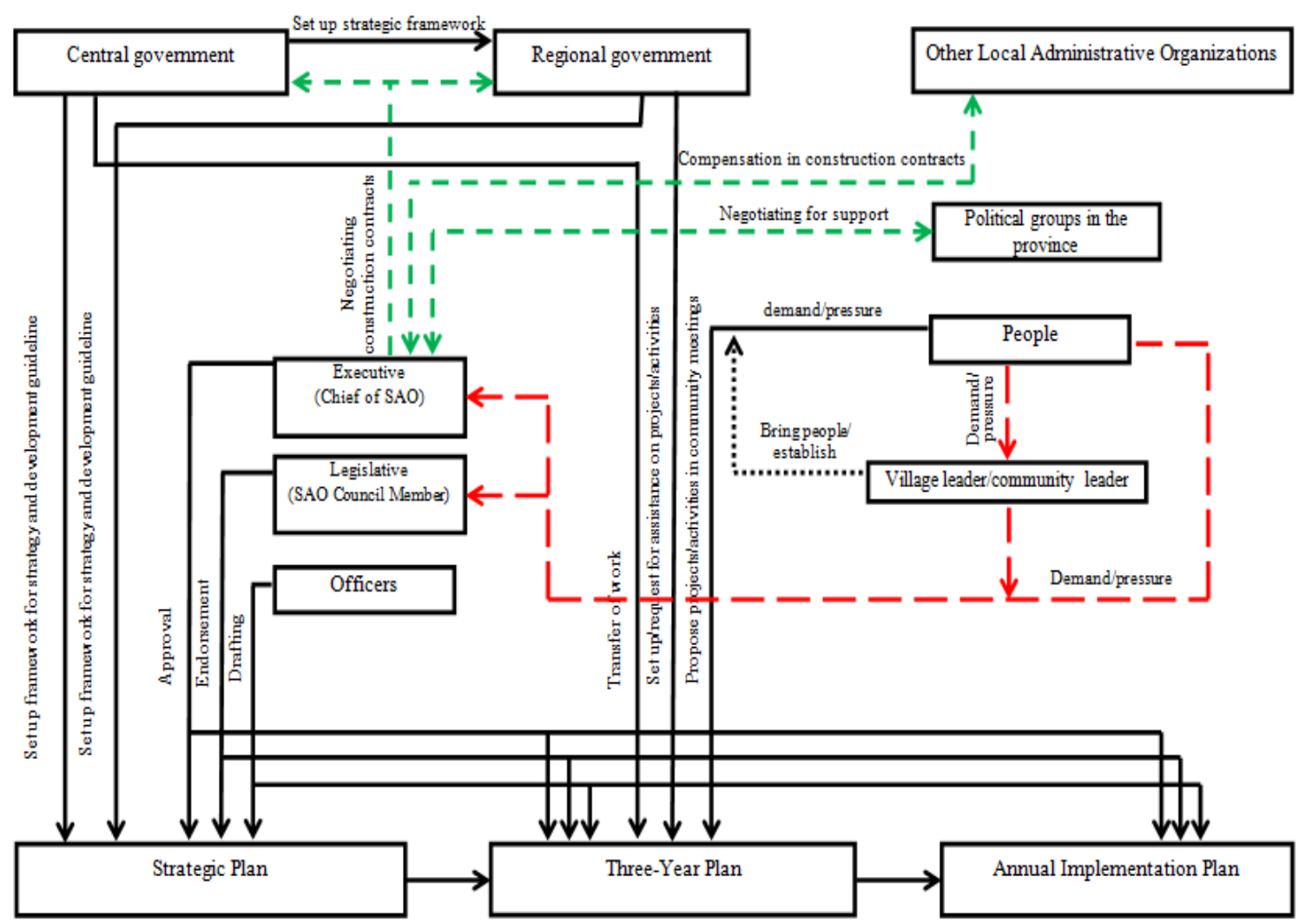

Figure 3. Politics in the process of establishing a local development plan of the Lan Tak Fah Subdistrict Administrative Organization

There are three initial presumptions before undertaking this research: (1) village people are not very keen in participating in the process of establishing a local development plan of the subdistrict administrative organization, both in the number of participants and diversity of the people who actually participate, resulting in people cannot fully have an opportunity to participate in the process; (2) area officers and local officers have quite a bigger role in establishing local development plan than that of people both in the dimension of identifying problems in order to propose projects to utilize the budget and in making decisions to choose projects; and (3) rules, regulations, and procedures in establishing a local development plan contain problems and obstacles in themselves in the aspect of allowing for participation of people. However, the research results indicate as follows:

(1) It is not that village people lack interests in participating in the process, but the mechanism in setting a plan only gives minimal opportunities to people to only participate by indicating problems and needs. The projects appeared in the plan turn out to have no clear budgetary support. Furthermore, people's participation is used by the administration of the subdistrict administrative organization to claim that people have already participated in the process by attending the community meetings, which are part of the process. In addition, the administration gives a reason of no budget available to implement the projects for people's needs, which is used as a claim to discourage people to follow up with their questions regarding a solution to their problems and needs. Accordingly, people are pushed away from the participation under the main objective of local development planning. This type of participation is also considered a very low level of participation under the theory of participation because people actually only receive information. Also, they participate in the process because they are asked or forced to participate due to the power-related relationship or group dependency. This is all reflected 
by people that they were interested in participating but they later felt upset because their participation was used as a "photograph" for the executive people and officers who established the plan, to show that they have let people to participate. In another word, people turn out to be only a rubber stamp for the executives and officers.

Pataravadi Boonraksa (2010) concluded her study on "People's Participation in the Government Development Plan: Case Study of the Three-Year Development Plan (2011-2556) Chong Mek Subdistrict Municipality, Sirindhorn, Ubon Ratchathani" that the problems of peoples' participation in the process of establishing the local development plan are lack of publicities, people without role in the society, and lack of real opportunity to participate. Her study is based on a measurement of knowledge about participation. However, the actual participation in that study was still under the limitation of proposing problems and needs to be placed in the Three-Year Development Plan, which shows only limited participation of people in the process. There was no chance for people to participate at the level of making a demand for the projects' implementation to actually answer to the needs of peoples. According to the empirical research, the process in participation does not allow people to fully present their problems and needs. The minimal level of publicities even worsens the situation as it does not allow for an opportunity for people to realize the importance of participation.

(2) In the process of local development planning, especially in the community meetings, local officers, i.e. officers of the subdistrict administrative organization who run the meeting not only have an important role of directing the meeting, but such process also opens an opportunity to local officers, such as village leader and/or previous village leader, as well as Subdistrict Administrative Organization Council members to propose projects through votes of people in their network. Officers then will place those projects in the Three-Year Development Plan and approve budget to implement those projects, applying the mechanism of the Subdistrict Administrative Organization Council through the votes of Subdistrict Administrative Organization Council members so that the budget is approved for the projects placed in the Plan. With this feature, people participating in the community meetings are only utilized to endorse only certain community's problems or needs.

(3) Rules, regulations, and procedures in establishing the subdistrict administrative organization development plan are determined by the central government, i.e. setting a structure and framework step by step in order to be consistent with the National Economic and Social Development Plan and other plans in the lower levels. This policy setting framework does not give an opportunity to people to participate in it. Participation of people in localities is limited to only presenting their problems and needs as proposals in a project format to be consistent with the policy which is set for them to only accept those projects. This is because participation of people is framed only to the level of hearing information of the development strategic plan, which cannot change any development strategy already required in order by the central government. Another part of participation is proposing problems and needs to be placed as the projects in the Three-Year Development Plan, including ranking priorities of the problems. The best level of this type of participation is merely pushing the problems and needs to be placed in the Three-Year Development Plan. People do not have any opportunity to participate in demanding, making decisions or monitoring the management of budget and resources of the subdistrict administrative organization. Therefore, the selection of projects to be implemented under the budget without peoples' opportunity to see the management procedure in this part, causes people not to realize their rights to participate in the work of their local office. Even the detail in holding community meetings in the Manual for Establishing Local Development Plan, Strategic Plan for Development, Three-Year Development Plan, Implementation Plan and Monitoring and Assessment, prepared by Local Development Division, Bureau of Local Development and Management Promotion, Department of Local Administration, does not make any effort to allow village people to conduct the community meetings on their own. Letting people conduct and lead themselves in those meetings would likely help them understand the overall picture and the significance of participation as well as realization of their rights in other levels.

Chamaipond (2009) indicates in her study titled "People's Participation in Determining Local Development Plan" that rules, regulations, and procedures in establishing a development plan of subdistrict administrative organizations have problems and obstacles in issues of steps for people's participation. The problems start from determination of development strategies as the Ministry of Interior's Regulation on Establishing Local Development Plans 2005 requires "the steps to begin with establishing the development strategic plan to be followed by the three-year development plan which has to be consistent with the development strategic plan, and then to adjust the local development plan to practice through an implementation plan." Therefore, it should be specially considered about the participation of people at the step of determining the development strategic plan. Chamakul pointed out that, as stated in a legal provision, the information received in the local meetings is simply basic information for consideration; particularly after providing such information in the local community meetings, people no longer has any role in determining development strategic planning. This leads to a 
conclusion that such provision does not sufficiently facilitate people's participation in the local development work with local administrative organizations. The empirical analysis of information and data from participant observation confirms that not only does the provision give a very limited opportunity to people to participate in the public work in the localities, but the implementation of that provision by local administrative organizations is not complete. It defaults at the step, as indicated by Chamakul, which actually needs special attention. This further implies that the problems and obstacles do not arise out of the rules and regulations, but from the process set by local administrative organizations, which does not open an opportunity to people to be able to participate in making political decisions as provided for under those rules and regulations.

\section{Recommendations}

(1) It should be noted that there was no community meetings in order for officers to learn about the peoples' problems, needs, development issues, and other issues in order to set up a guideline to establish the development strategic plan. Further, the study (through participant observation and documentary research) also shows that personnel of the subdistrict administrative organization who led the community meetings did not have sufficient skills or capabilities to help people brainstorm ideas and to discuss the community's needs seriously. Even the priority order of almost projects/activities proposed in the community meetings can be easily framed by Council members or community leaders. A short-term recommendation is to increase the skills of subdistrict administrative organizations' personnel up to the same standard so that they are capable of leading community meetings efficiently.

(2) Under this study, the researchers also found that the current mechanism to give an opportunity to people to participate in the local development planning process is insufficient to increase the negotiating power of people to share the community resources equally, efficiently, and, after all, directly and actually reflecting the needs of people without the government's overshadowing in the process. In addition to fully monitoring and following up with the work of subdistrict administrative organizations as provided in the procedure, especially the community meetings, the researchers recommend that in the medium term, there should be studies and establishment of a mechanism to perform the check-and-balance function as the "Local Citizen Committee" with the power to consider the principles in selecting and approving projects from the annual implementation plan. In each meeting of the Council members, the Local Citizen Committee will act similarly to the jury in the court of the United States to elaborate on the facts and opinions presented at those meetings. This will help fill in the gap at present and provide people with the negotiating power against other groups in the community and to allow them to have more equal opportunity than that at present.

(3) As for the long-term recommendation to solve the problems at the root cause of behavior of less participating in the political process of establishing a local development plan. Different players must better understand the principle of "decentralization"; the central and regional governments must decrease their role in dominating the strategy and guideline for local administrative organizations development. Local administrative organizations should be given an opportunity to determine the strategy and development guideline to be consistent with the needs of people in their area. This will be coherent with the statement of Anek (2014) which indicates that "unless there is an appropriate change in the regional administration (including central administration - commented by the researchers), it is useless to undertake a serious reform in local administrations.

Nevertheless, local administrative organizations themselves must realize the principles abovementioned that giving full opportunities to people to participate in the processes of determining, monitoring, and examining the work of local administrative organizations so that the needs of people can be directly addressed. This ideology must not be neglected and instead must actually be provided for and efficiently executed.

\section{References}

Barber, M. (1974). Public Administration. Hertford-shire: Garden City.

Boonraksa, P. (2010). People's Participation in the Government Development Plan: Case Study of the Three-Year Development Plan (M.A. dissertation). Chulalongkorn University.

Boontongkum, N. (2012). People's Participation in Establishing Subdistrict Development Plan of Ta-Pon Subdistrict Administrative Organization (M.A. dissertation). Phetchabun Rajabhat University.

Bunleng, P. (2005). Establishment of Five-Year Development Plan by People's Participation in Chiang Mai City Municipality (M.A. dissertation). Chiang Mai University.

Chairat, A. (2011). Level of People's Participation in Establishing Development Plan of Baan-Na, Kaper, Ranong. Special Problem (M.A. dissertation). Burapha University. 
Chamakul, C. (2009). People's Participation in Determining Local Development Plan (M.A. dissertation). Chulalongkorn University.

Chotkunpan, I. (2011). People's Participation in Establishing Budgets of Subdistrict Administrative Organizations: Analysis on the Subdistrict Administrative Organization which Won an Award on People's Participation (M.A. dissertation). Chulalongkorn University.

Chuket, S. (2014). Policy and Plan Analysis Officer. Acting Chief of the Permanent Secretary Office Interview.

Department of Local Administration. (n.d.). Manual for Establishing Local Development Plan, Strategic Plan for Development, Three-Year Development Plan, Implementation Plan and Monitoring and Assessment. Bangkok: Local Development Division, Bureau of Local Development and Management Promotion, Department of Local Administration.

Dongtongsang, N. (2014). Village Citizen of Moo 5. Interview.

Kaewhanam, K. (2012). Participation in Municipality Development Planning: The Comparison of Khon Kaen Municipality and Kalasin Municipality. Thai Journal of Public Administration.

Kaewpangmak, N., \& Galantapura, O. (2014). People's Participation in Establishing Development Plan of Subdistrict Administrative Organizations in Bangsai, Ayutthaya. Journal of Interdisciplinary Research: Graduate Studies, 3, 215-227.

Kruatep, W. (2010). People's Participation in Establishing Budget of Subdistrict Administrative Organizations. Bangkok: Faculty of Political Science, Chulalongkorn University.

Lan Tak Fah Subdistrict Administrative Organization. (2014). Report of Village Community Meetings to Establish the Development Strategic Plan and the Three-Year Development Plan. Nakhon Pathom: Lan Tak Fah Subdistrict Administrative Organization.

Laothamatas, A. (2014). The Cause is in the Localities. Pathum Thani: Klangpanya Institution, Rangsit University.

Lertkrai, A. (2014). People's Participation in Establishing Local Development Plan by Holding the Principle of People as the Center: Case Study for the Krabi Provincial Administrative Organization. In K. Jermsittiparsert, M. Muthuta, \& P. Siriattakul (Eds.), Proceedings of the $1^{\text {st }}$ National and International Conference on Humanities and Social Sciences (pp. 439-447). Bangkok: Political Science Association of Kasetsart University.

Munkit, K. (2008). Participation of Community Leaders in Preparing the Development Plan of Cha-Am District Municipality (M.A. dissertation). Suan Dusit Rajabhat University.

Paipad, N. et al. (2010). Participation of Community in Establishing Subdistrict Development Plan: Study on the Case of Kamalasai Subdistrict Administrative Organization, Kamalasai, Kalasin. Research and Development Health System Journal, 3, 61-73.

Prasanwong, N. (2014). President of the Baan Chanode Community Enterprise of Klongyone Community-Lan Tak Fah. Interview.

Sabua, D. (2013). People's Participation in Establishing Community Plan of Cha-Mab Subdistrict Administrative Organization. Academic Review, 1, 61-68.

Sinkasem, V. (2014). Permanent Secretary of the Lan Tak Fah Subdistrict Administrative Organization. Interview.

Siripin, S. (2014). Village Citizen of Moo 4. Interview.

Sirorod, P. (2014). Public Policy Dynamics: From State and Private Sectors to People (2nd ed). Bangkok: Kob-Fai Publication Project.

Srisa-art, B. (1992). Initial Research. Bangkok: Suviriyasarn.

Sriwongsa, N., \& Charoensuk, J. (2014). People's Participation in Establishing Development Plan of Koke-Sawang Subdistrict Administrative Organization. Journal of Politics and Governance, 4, 296-313.

Supivek, S. (2014). Chief of the Lan Tak Fah Subdistrict Administrative Organization. Interview.

Suwannamala, C., \& Kruatep, W. (2011). Challenges in Decentralization and Local Administrations in Thailand. Bangkok, Center for Local Innovations and Governance.

Tapanadhamchai, W. (2013). Strategy of Reinforcing People's Participation in Developing Prong Ma Dua 
Subdistrict Municipality, Muang, Nakhon Pathom. Academic Services Journal, 24, 94-108.

Tapthani, S. (2012). People's Participation in Establishing Local Development Plan of Subdistrict Administrative Organizations in Nonghan, Udon Thani. Phetchabun Rajabhat Journal, 14(2), 89-99.

Tongsima, S. (2014). Village Citizen of Moo 5. Interview.

Unchaoban, C., Chujit, T., \& Chujit, S. (2008). Problems in Establishing Development Plan of Phichit Provincial Administrative Organization (M.A. dissertation). Naresuan University.

Yoongtong, K. (2012). Participation of People in Preparing the Development Plan of Na-Ngua Subdistrict, Muang, Phetchabun: Case Study of Level of Participation of People in Praparing Na-Ngua Subdistrict Municipality Development Plan (M.A. dissertation). Phetchabun Rajabhat University.

Yumwilai, K. (2011). Participation of People in Preparing Three-Year Development Plan of Bangmoonnak Municipality (M.A. dissertation). Naresuan University.

Wattanakornkaew, V. (2014). Council Member of the Lan Tak Fah Subdistrict Administrative Organization, Moo 5. Interview.

\section{Note}

Note 1 . In the record after the end of the meeting at 14:00 hrs, there were only 34 signatures, but after examining the document at the subdistrict administrative organization afterwards, it was found that there were 49 signatures and one of the additional names was Sarawut Sukpol, who was the same person signing at the first time.

\section{Copyrights}

Copyright for this article is retained by the author(s), with first publication rights granted to the journal.

This is an open-access article distributed under the terms and conditions of the Creative Commons Attribution license (http://creativecommons.org/licenses/by/3.0/). 